\title{
Martial arts intervention decreases pain scores in children with malignancy
}

\author{
Martin H Bluth ${ }^{1,2}$ \\ Ronald Thomas ${ }^{3,4}$ \\ Cindy Cohen ${ }^{2}$ \\ Amanda C Bluth ${ }^{5}$ \\ Elimelech Goldberg ${ }^{2,4}$ \\ 'Department of Pathology, Wayne \\ State University School of Medicine, \\ Detroit, MI, ${ }^{2}$ Kids Kicking Cancer, \\ Southfield, MI, ${ }^{3}$ Children's Research \\ Center of Michigan at Children's \\ Hospital of Michigan, Detroit MI, \\ ${ }^{4}$ Department of Pediatrics, Wayne \\ State University School of Medicine, \\ Detroit, MI, ${ }^{5}$ Wayne State University, \\ Detroit, MI, USA
}

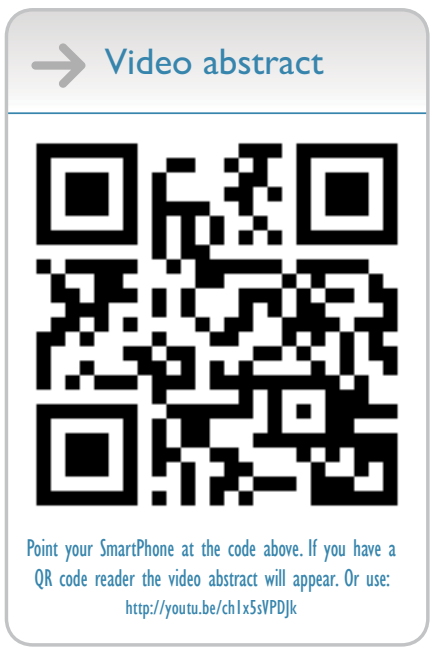

Correspondence: Martin H Bluth Department of Pathology, Wayne State University School of Medicine, Detroit, 540 E Canfield Street, MI 4820I, USA $\mathrm{Tel}+|91784| 7409$

Email mbluth@med.wayne.edu
This article was published in the following Dove Press journal:

Pediatric Health, Medicine and Therapeutics

8 July 2016

Number of times this article has been viewed

Background: Martial arts intervention in disease has been mostly limited to adult inflammatory, musculoskeletal, or motor diseases, where a mechanical intervention effects positive change. However, the application and benefit to pain management in childhood malignancy are not well described. Here, we assess the effects of defined martial arts intervention in children with cancer with respect to their pain perception and management.

Methods: Sixty-four children with childhood malignancies were enrolled in a martial arts program, which encompassed both meditation and movement modalities. Pain scores (0-10) were recorded pre- and post- 1-hour session intervention. Pain scores were crossed by total visits and tabulated by whether participant pain reduced at least 1 unit, stayed the same, or increased in intensity immediately after (post) participation session. Differences in pain scores were further compared by age and sex.

Results: Prepain and postpain scale data were measured for 64 participants, 43 males $(67.2 \%)$ and 21 females (32.8\%), ranging from 3 years to 19 years. Preintervention and postintervention data were obtained for 223 individual session visits. Mean number of patient participation visits was $1.8 \pm 1.6$ (range one to nine visits). Of 116 individual measured sessions where the participants began with a pain score of at least 1 , pain intensity reduced $\geq 1$ unit in $85.3 \%(99 / 116)$ of visits, remained the same in $7.8 \%(9 / 116)$, and increased in $6.9 \%(8 / 116)$. For the majority $(96.3 \% ; 77 / 80)$ of sessions, participants began with a prepain intensity score of at least 5-10 with reduction in pain intensity following the session. The overall mean pain score presession visit was reduced by $\sim 40 \%$ (pre: $5.95 \pm 2.64$ and post: $3.03 \pm 2.45$ [95\% CI: $2.34-3.50$ ]; $P \leq 0.001$ ). Median pain intensity scores had greater reductions with increased age of participants (3-6 years [-1], 7-10 years [-2], 11-14 years [-3], and 15-19 years [-4]).

Conclusion: Martial arts intervention can provide a useful modality to decrease pain in childhood cancer, with greater effect achieved with higher baseline pain scores and patient age. Martial arts intervention may improve patient compliance with respect to medical and surgical management, thus reducing disease morbidity and health care costs.

Keywords: martial arts, karate, cancer, pain, intervention, therapy

\section{Introduction}

Cancer continues to dominate the health care landscape. ${ }^{1}$ Although administration of pharmacological agents constitutes the major intervention in this disease space, other "nondrug" therapies constitute a significant component of the psychosocial-economic opportunity with respect to treatment. Much of the interventions with regard to cancer treatment, vis-a-vis both pharmacological and nonpharmacological modalities, focus on controlling the pain associated with this disease. Indeed, cancer pain accounts for 
considerable costs and may also contribute to noncompliance either as a result of treatment regimens or patients' quality of life. ${ }^{2-4}$

Pediatric cancer contains another layer of complexity in that the patient often refers to the unit of the father, mother, and child, and as such, may affect compliance to therapy, the perception of pain, and quality of life. Other variables including the patient's other relatives and belief structure, provide additional considerations. ${ }^{5-8}$ Various modalities have been used to address pediatric cancer pain. Although pharmacological options have been used to decrease pediatric pain, barriers to successful implementation include parents' reluctance to their child receiving pain medication, inadequate information/education pertaining to physician medication orders, subjective pain perception and severity scores, and fear of addiction or tolerance to pain medication among others. ${ }^{8-10}$ Insurers are eager to adopt interventions for controlling cancer pain (pediatric and adult), since this would facilitate considerable cost saving to the health care industry as a means to increase patient compliance to therapy and disease management as well as to decrease other morbidities. ${ }^{11-14}$

The application of martial arts in health maintenance has been well documented. Both physical (Karate, Tai Kwon Do, etc) and meditative (Tai Chi and Chi[Qi] Gung, etc) modalities within the scope of martial arts have been shown to increase flexibility, range of motion, mental focus, and decrease anxiety and stress. ${ }^{15-17}$ Martial arts facilitate control over oneself and include different aspects of metered breathing, guided imagery, and physical as well as mental conditioning to overcome challenges. The positive effects of martial arts in disease states have also been described. Recent studies have shown that rheumatoid arthritis patients who practiced Tai Chi 50 minutes/week for 12 weeks had decreased pain and fatigue when compared with routine care. ${ }^{18,19}$

Similarly, patients suffering with osteoarthritis or fibromyalgia, where there are less effective disease-modifying agents than for rheumatoid arthritis, can also benefit from Tai Chi. ${ }^{20-22}$ In those studies, implementation of distinct Tai Chi regiments, either short form or long form (which pertains to the number of postures per form), has been correlated with positive findings pertaining to improved muscle strength, endurance, reduced stress, psychological well-being, flexibility, and muscle control. Even in pilot studies where there were no observed differences between Tai Chi and control groups over a 4-8-week regimen, ${ }^{23}$ participants generally “preferred Tai Chi to their previous physiotherapeutic intervention, finding it more useful and more enjoyable". Furthermore, the implementation of Tai Chi to other diseases including
Parkinson's ${ }^{24}$ and heart diseases ${ }^{25}$ has also been reported. Regarding malignancy, a recent meta-analysis demonstrated positive effects of Tai Chi and Qigong in adult cancer patients in improving their quality of life and decreasing markers of inflammation (C-reactive protein and cortisol). ${ }^{26}$

Although there are reports of the application of martial arts in other disease states with demonstrations of beneficial effects, here we describe the effects of martial arts as an interventional therapeutic modality to reduce pediatric cancer pain. This program is further adaptable to hospital and clinic settings as well as noncancer pediatric disease space, thus providing widespread accessibility toward the control and mitigation of pediatric pain.

\section{Methods}

Sixty-four children with childhood malignancies were enrolled in the martial arts therapy program, which encompassed both the meditative aspects of martial arts and the actual movements and techniques used in that discipline over the course of 12 months. The intervention was administered by specially trained martial arts instructors according to the standard operating procedures of the organization Kids Kicking Cancer (www.kidskickingcancer.org) and patient consent was obtained prior to intervention. Each program consists of a 1-hour session, where patients are exposed to a mix of martial arts-based therapeutic interventions, either individually or in group setting. The session begins with identifying each child participant's (presession) pain rating as well as location of pain and cause where applicable (ie, "my pain was $7 / 10$ after having chemotherapy, line/catheter/port placement, and/or injections", etc). Pain scores are recorded using an 11-point (0-10) verbal and/or continuous visual analog scale. The visual analog scale is a psychometric response scale commonly used in questionnaires to measure pain as an instrument for subjective characteristics or attitudes that cannot be directly or objectively measured. The participant begins with a "body scan" in which children lie down and begin to meditate, focusing upon the sensation of their breath. After a few moments (times differ based on the age and attention level of the group), the students are asked to imagine themselves perceiving their bodies beginning from the top of their head and proceed downward through their body relaxing the different muscle group on the voice direction of the "sensei" (martial arts instructor). The "body scan" also helps each participant focus on and become cognizant of each body part with respect to pain/fear/frustration and function and gently allows any unpleasant sensations to flow out of their body. The session continues with karate style martial arts movements modified for each patient according to his or 
her capabilities. After 30 minutes, participants rehydrate and discuss how they have used their breathing and meditation therapeutic techniques during that week to "bring in the light and blow out the darkness" of their procedures or medical situations. Each child defines his or her "darkness" (ie, "IV placement in the hand vein") and is invited to share with the class how they triumphed during the week using their "light" (via breath/meditation) to push out the darkness. This provides an individualized and collective patient empowerment as well as affirmation of successful pain management (participants are referred to as "powerful martial artists" and that "pain is a message that we do not have to listen to").

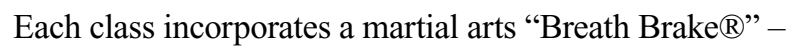
a modality that incorporates three cycles of "breathing in (metered inhalation with slight lifting of the chest/body)" for 3 seconds, "holding (maintaining)" the breath for 3 seconds, and "breathing out (metered exhalation, where chest/body is slightly lowered and relaxed)" for 3 seconds, each time envisioning "breathing in the light and breathing out the darkness". The remaining 30 minutes include individualized or small group sessions, which focus on different aspects of martial arts movements and exercises, and further internalizing the concepts via physical touch points of parenthetically breaking the pain with punches and kicks as well as allowing the pain to pass through the individual by using the image of the breath to pass through and relax the area in pain. Because children on chemotherapy often have brittle bones, there are never any breaks or sparring involved in the program. However, the children do punch or kick a soft rubber target mitt when able. As the martial arts are focused on imagery, the children are invited to see their target as their disease, pain, anger, or any "darkness" the children choose. The children are asked to image themselves "destroying" their disease or whatever they define as the "darkness" and "see" it shatter with perceived reduction.

As the martial arts are "ritually oriented", the children have a special bow and "karate yell" that they are asked to do several times during the class. At Kids Kicking Cancer, the children bow and call out the mantra "Power, Peace, Purpose"TM. "Power" represents each child's ability to bring in a powerful martial arts energy. "Peace" represents how a child can blow out the pain, fear and sadness that he/she may face. "Purpose" represents each child's ability to project their triumph and "Teach the world" that pain, stress and adversity can be overcome. Because the pediatric patients face such darkness, their parents, caregivers, nurses, and doctors also become participants and also learn from them how to face down the stressors in their adult lives, further augmenting the positive influence of the program. The session concludes with another round of "power breathing" and post session pain scores. These studies were approved by the participating institutional review boards of Brooklyn Hospital Medical Center, Columbia Presbyterian Medical Center, and Maimonides Medical Center.

\section{Statistical analyses}

Patient demographic and descriptive visit data were assessed using mean values, standard deviations, median values, modes, ratios, and proportions. The range of pain scores (overall $\geq 1$ and within categories from 1 to 10 ) was crossed by total visits and tabulated by whether participant pain reduced at least 1 unit, stayed the same, or increased in intensity immediately after (post) participation session. From our perspective, a minimally clinically important reduction in pain is assigned to any lowering of pain level that children are able to accomplish. Furthermore, although any reduction in pain is clinically worthwhile in children, achieving greater reductions could be considered more important in pain relief than reductions in lower scores.

The percentage of change in pain intensity after session was recorded to depict whether pain intensity reduced, stayed the same, or increased pre-/postvisit, where pain intensity reduced by at least 1 unit postintervention with ranges of pain intensity, minimum and maximum values, and interquartile ranges. Nonparametric Wilcoxon signed rank test for related (paired) samples was conducted for those which reported at least a pain intensity score of 1 presession with postsession scores. Mean percent change scores were also table reported by prepain score category of pain (on a scale of $1-10$ of increasing pain) by visits. Median prepain and postpain intensity change scores were further compared between four age categories using a nonparametric Kruskal-Wallis procedure, followed by pairwise comparisons conducted using a nonparametric Mann-Whitney $U$ test. Age groups were created by using $\sim 25 \%$ cutoffs in the frequency age range. Nonparametric Mann-Whitney $U$ test compared prepain and postpain difference scores by sex. Nonparametric Spearman's Rho correlation coefficient was conducted to examine if a possible relationship existed between prepain and postpain intensity scores and age. Statistical significance was considered achieved at $P \leq 0.05$. All statistical procedures were conducted using SPSS Version 22, IBM Corporation (Armonk, NY, USA).

\section{Results}

Weekly pre- and postpain scale data were measured for 64 participants, 43 males (67.2\%) and 21 females (32.8\%; Table 1). Their ages ranged from 3 years to 19 years, with a 
median of 11 years, a mean of $11.2 \pm 3.9$ years, and a mode of 12 years, and represented varied ethnicities (Caucasian 31\%, African American 28\%, Hispanic 33\%, and Asian 5\%). Preand postintervention data were obtained for 223 individual session visits. In all, 48.0\% (107/223) of participants reported no pain (zero) prior to their presession, who were excluded from subsequent analysis. Data analyses therefore concentrated on those participants and visits where prepain intensity scores were recorded as $\geq 1$. Sessions occurred weekly; however, participant pain scores were not measured every week, due to holidays and some absences. Mean number of patient

Table I Participant demographics

\begin{tabular}{ll}
\hline Participants & $\mathbf{n}=\mathbf{6 4}$ \\
\hline Sex & \\
Male & $43 / 64(67.2 \%)$ \\
Female & $21 / 64(32.8 \%)$ \\
Ethnicity & \\
Caucasian & $20 / 64(31.3 \%)$ \\
African American & $18 / 64(28.1 \%)$ \\
Hispanic & $21 / 64(32.8 \%)$ \\
Asian & $3 / 64(4.7 \%)$ \\
Age (years) & \\
Mean $\pm S D$ age & $11.2 \pm 3.9$ \\
Median age & 11.0 \\
Mode age & 12.0 \\
Age range & $3-19$ \\
Session visits & \\
Mean $\pm S D$ no of visits & $1.8 \pm 1.6$ \\
Median no of visits & 1.00 \\
Range visits & $1-9$ \\
\hline
\end{tabular}

participation pre- and post- (same day) measured visits was $1.8 \pm 1.6$, with a range of visits from one to nine visits.

Participants began their session visits ranging in pain scale score from $\geq 1$ to as high as 10 . Of 116 individual measured sessions where the participants began with a pain score of at least 1 , pain intensity reduced $\geq 1$ unit in $85.3 \%$ $(99 / 116)$ of visits, increased in $6.9 \%(8 / 116)$, and remained the same in $7.8 \%(9 / 116$; Figure 1$)$.

Table 2 represents the range of pain intensity scores for participants who had a pain score of 1 or greater prior to their visit (overall $\geq 1$ and within categories from 1 to 10 ) crossed by total visits and tabulated by whether participant pain reduced at least 1 unit, stayed the same, or increased in intensity after (post) weekly participation session. In total,

Table 2 Pain reduced at least I unit on pain scale immediately after (post) weekly participation session, $\mathrm{n}(\%)$

\begin{tabular}{lllll}
\hline $\begin{array}{l}\text { Prepain score } \\
\text { before session }\end{array}$ & $\begin{array}{l}\text { Total no } \\
\text { of visits }\end{array}$ & Yes & No & Stayed the same \\
\hline 1 & 12 & $2(17)$ & $4(33)$ & $6(50)$ \\
2 & 3 & $2(67)$ & $1(33)$ & 0 \\
3 & 9 & $8(89)$ & $1(11)$ & 0 \\
4 & 12 & $10(83)$ & $2(17)$ & 0 \\
5 & 9 & $9(100)$ & 0 & 0 \\
6 & 9 & $9(100)$ & 0 & 0 \\
7 & 24 & $22(92)$ & 0 & $2(8)$ \\
8 & 18 & $17(94)$ & 0 & $1(6)$ \\
9 & 14 & $14(100)$ & 0 & 0 \\
10 & 6 & $6(100)$ & 0 & 0 \\
Total $(>1)$ & 116 & $99(85)$ & $8(7)$ & $9(8)$ \\
\hline
\end{tabular}

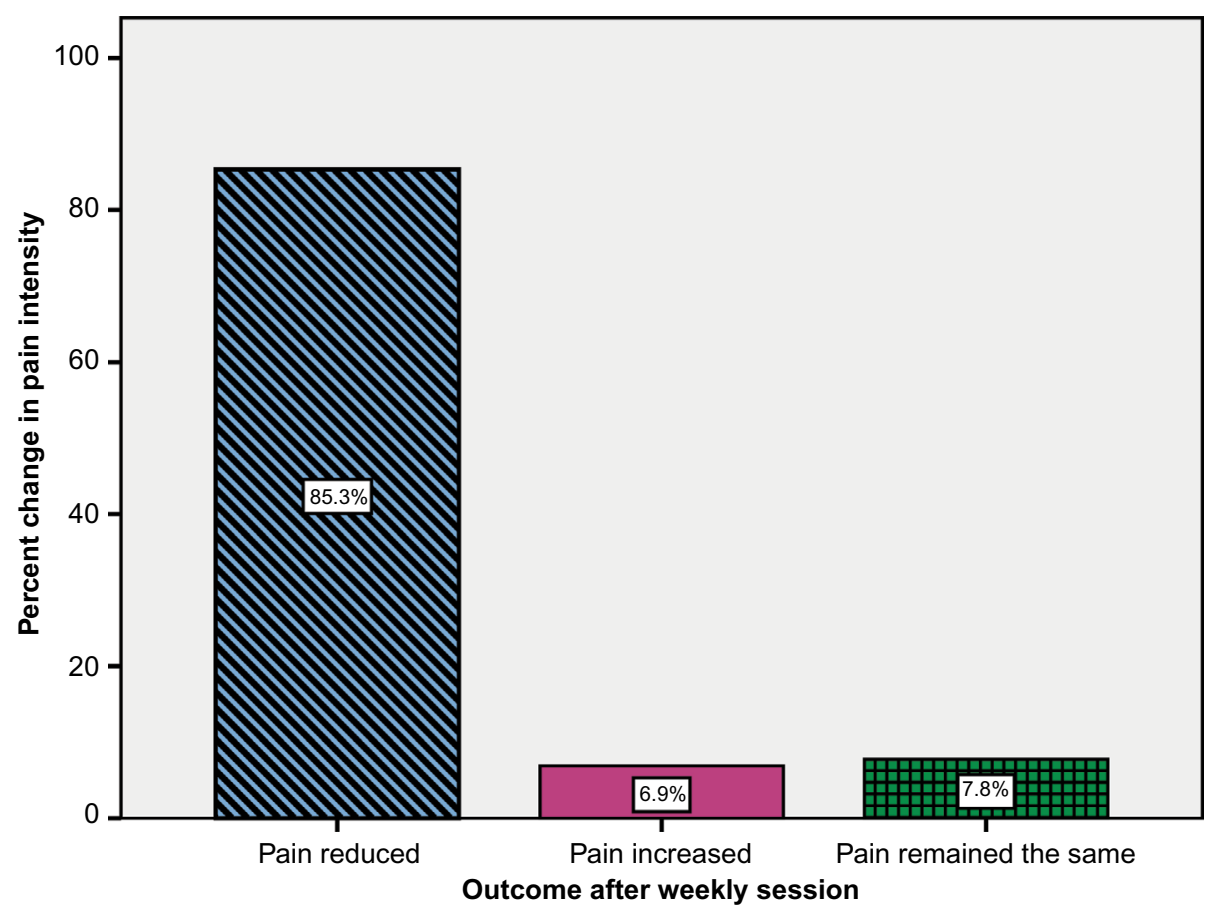

Figure I Pain intensity outcome after weekly session $(n=\mid 16)$. 
for all visits $85 \%$ of participants demonstrated at least one point reduction in pain, $7 \%$ demonstrated an increase, and $8 \%$ remained the same. Of these, the majority of individual visits started with pain scale scores of 3 or greater, with the largest pain intensity scores presession being in the range of 7-9 (48.2\%; 56/116 visits). Interestingly, the majority (96.3\%; $77 / 80$ ) of individual sessions where participants began with a prepain intensity score of $\geq 5$, reduced in pain intensity following the session; in these participants, only three remained the same and none increased in pain intensity postsession.

Table 3 represents the overall mean prepain and postpain scores of session visits for those who began the session with at least a pain score of 1 or higher. The overall mean pain score presession visit $(\mathrm{n}=116)$ was $5.95 \pm 2.64$, which reduced to $3.03 \pm 2.45$ postsession. The median value presession was 5.00 and postsession was 3.00 . The interquartile value of pain intensity reduced from prevalues of 4.00 (25th percentiles) and 8.00 (75th percentiles) to postvalues of 1.00 and 5.00 , respectively. The overall median pain score significantly reduced from 5.00 to 3.00 ( $40 \%$ reduction; $\leq 0.001)$.

Table 3 Participant visits where pain reduced at least I unit

\begin{tabular}{lll}
\hline & Pain before & Pain after \\
\hline $\mathrm{N}$ (visits) & 116 & 116 \\
Mean & 5.95 & 3.03 \\
Median & 5.00 & 3.00 \\
Mode & 7.00 & 0.00 \\
Standard deviation & 2.64 & 2.45 \\
Difference between minimum and & 9 & 8 \\
maximum in range & & \\
$\quad$ Minimum & $\mathrm{I}$ & 0 \\
$\quad$ Maximum & 10 & 8 \\
Percentiles 25 & 4.00 & 1.00 \\
Percentiles 75 & 8.00 & 5.00 \\
\hline
\end{tabular}

Table 4 Mean percent change in pain scale scores immediately after (post) weekly participation session

\begin{tabular}{lll}
\hline $\begin{array}{l}\text { Prepain score before } \\
\text { session }\end{array}$ & $\begin{array}{l}\text { Total number } \\
\text { of visits }\end{array}$ & Mean \pm SD \\
\hline$\geq 1$ & 116 & $-24.4 \% \pm 1.4 \%$ \\
$\geq 2$ & 102 & $-51.7 \% \pm 41.2 \%$ \\
$\geq 3$ & 99 & $-52.8 \% \pm 36.0 \%$ \\
1 & 12 & $+2.1 \% \pm 3.5 \%$ \\
2 & 3 & $-16.7 \% \pm 1.4 \%$ \\
3 & 9 & $-44.4 \% \pm 50.0 \%$ \\
4 & 12 & $-50.0 \% \pm 56.4 \%$ \\
5 & 9 & $-67.5 \% \pm 32.0 \%$ \\
6 & 9 & $-57.4 \% \pm 32.4 \%$ \\
7 & 24 & $-43.5 \% \pm 30.8 \%$ \\
8 & 18 & $-57.6 \% \pm 28.8 \%$ \\
9 & 14 & $-57.1 \% \pm 28.5 \%$ \\
10 & 6 & $-58.0 \% \pm 30.3 \%$ \\
\hline
\end{tabular}

Notes: $(-)$ sign indicates the mean percent reduction in pain; $(+)$ sign indicates the mean percent increase in pain.
Table 5 Change from highest presession to lowest postsession pain scores

\begin{tabular}{|c|c|c|c|c|c|c|c|c|c|c|}
\hline \multicolumn{11}{|c|}{ Lowest postsession pain score } \\
\hline \multicolumn{11}{|c|}{$\begin{array}{l}\text { Number of children with increased pain scores (bolded } \\
\text { numbers) }\end{array}$} \\
\hline $\begin{array}{l}\text { Highest presession } \\
\text { pain score }\end{array}$ & 0 & $\mathbf{I}$ & 2 & 3 & 4 & 5 & 6 & 7 & 8 & Total \\
\hline i & 2 & 6 & 0 & $\mathbf{0}$ & $\mathbf{0}$ & $\mathbf{0}$ & $\mathbf{0}$ & $\mathbf{I}$ & 3 & 12 \\
\hline 2 & 2 & 0 & 0 & 0 & $\mathbf{0}$ & $\mathbf{I}$ & $\mathbf{0}$ & 0 & $\mathbf{0}$ & 3 \\
\hline 3 & 2 & 2 & 4 & 0 & 0 & $\mathbf{I}$ & 0 & 0 & 0 & 9 \\
\hline 4 & 5 & 0 & 3 & 2 & 0 & $\mathbf{I}$ & 0 & $\mathbf{I}$ & 0 & 12 \\
\hline 5 & 3 & I & 2 & 2 & 1 & 0 & 0 & 0 & 0 & 9 \\
\hline 6 & 2 & 1 & 1 & 2 & 1 & 2 & 0 & 0 & 0 & 9 \\
\hline 7 & 4 & 0 & I & 2 & 5 & 7 & 3 & 2 & 0 & 24 \\
\hline 8 & 3 & 0 & 4 & 3 & 2 & 2 & 3 & 0 & I & 18 \\
\hline 9 & 2 & 2 & I & 0 & 2 & 2 & 3 & 2 & 0 & 14 \\
\hline 10 & 0 & I & 3 & 0 & 0 & 0 & 0 & I & I & 6 \\
\hline Total & 25 & 13 & 19 & 11 & 11 & 16 & 9 & 7 & 5 & 116 \\
\hline
\end{tabular}

Table 4 represents the mean percent change in pain intensity scores after (post) weekly session visit. Overall, where initial pain scores were $\geq 1$ (116 visits), pain was reduced by a mean percent of $24.4 \% \pm 1.4 \%$. Where initial pain scores were $\geq 2$ (102 visits), pain reduced by a mean percent of $51.7 \% \pm 41.2 \%$, and where beginning pain score was $\geq 3$ ( 99 visits), pain reduced by a mean percent of $52.8 \% \pm 36.0 \%$. Prepain intensity scores that began at 4 or higher experienced mean percent reduction in postpain scores ranging from $43.5 \%$ to $67.5 \%$.

Table 5 depicts the individual session changes that occurred for all 116 visits where the relationship of each presession to postsession pain score is reported in an individualized manner for each visit. For example, 24 participant sessions began with a prepain score of 7 . Of these, four participants reported a reduction of pain to 0 , one participant reported a reduction of pain to 2, five participants reported a reduction of pain to 4 , seven participants reported a reduction of pain to 5 , three participants reported a reduction of pain to 6 , and two participants remained the same from their presession score of 7 . No participants reported an increase in pain. The bolded values represent any prepain participant's score that increased after treatment. Only eight of 116 total sessions, representing $7 \%$ of the study participants, showed an increase from prepain scores, and nine participants remained the same as their preintervention pain scores. Thus, $>85 \%$ of those studied demonstrated a reduction from prepain scores after this intervention.

When pain intensity scores were further compared between four age categories (3-6 years, 7-10 years, 11-14 years, and 15-19 years; Table 6), median pain scores reduced 1 unit through each successive older age group, beginning at a median of -1.00 in the lowest age group (3-6 years) and reducing to a median of -4.00 in the oldest age group (15-19 years), $P \leq 0.001$. Median prepain 
Table 6 Reduction in pain scores by age groups

\begin{tabular}{llll}
\hline $\begin{array}{l}\text { Age group } \\
\text { (years) }\end{array}$ & Median & $\begin{array}{l}\text { Mean (standard } \\
\text { deviation) }\end{array}$ & $\mathbf{9 5 \%} \mathbf{~ C l}$ \\
\hline $3-6$ & -1.00 & $-1.83(1.9)$ & -3.9 to 0.2 \\
$7-10$ & -2.00 & $-2.84(3.4)$ & -4.1 to -1.6 \\
$11-14$ & -3.00 & $-2.94(2.0)$ & -3.6 to -2.3 \\
$15-19$ & -4.00 & $-4.10(3.5)$ & -5.4 to -2.8 \\
Overall & -2.00 & $-3.19(3.0)$ & -3.8 to -2.6 \\
\hline
\end{tabular}

and postpain difference scores between males $(-3.00)$ and females $(-3.00)$ were identical (data not shown). In addition, all three ethnic groups experienced reductions in their mean prepain and postpain scores intervention; Caucasians reduced their pain scores by almost 3 units $(2.99 \pm 3.01)$, African Americans by $2 \frac{1}{2}$ units (2.47 \pm 3.19$)$, and Hispanics recorded slightly less reductions in pain scores (1.76 \pm 2.78$)$; however, the differences were not statistically significant ( $>0.05$; data not shown).

\section{Discussion}

The application of martial arts-related regimens in disease states is not well understood. Many of the studies that assess the effects of martial arts centralize around movement anomalies, which may be subject to mechanical or inflammatory processes in addition to its well-known effects to improve general psychological well-being. ${ }^{15-20,23,24}$ Recent data on the effects of biological effects of martial arts have also been described. To this end, Ho et $\mathrm{al}^{27}$ reported an increase in blood CD34+ progenitor cells in those engaged in the practice of Tai Chi suggesting its value as an antiaging therapy, while Chyu et $\mathrm{a}^{28}$ reported an increase in serum insulin growth factor 1 levels, facilitating promotion and maintenance of muscle mass and neuronal function in overweight/obese premenopausal women who participated in a martial arts exercise intervention. ${ }^{29,30}$

The application of martial arts intervention in cancer has also been described. Recent data suggest that such modalities can be valuable as a means to improve physical and psychological quality-of-life parameters in their relation to treatment. ${ }^{26}$ In those studies, the authors conduct a metaanalysis of the literature, which presents reports that martial arts intervention in cancer patients reported 1) less depressive symptoms, ${ }^{31}$ 2) stability of insulin levels, ${ }^{32} 3$ ) improvement in self-esteem ${ }^{33}$ and social/family well-being, ${ }^{34} 4$ ) strength and flexibility, ${ }^{35} 5$ ) cognitive function, ${ }^{36} 6$ ) survival, ${ }^{34}$ and 7) inflammatory/metabolic markers such as C-reactive protein and cortisol ${ }^{36,37}$ compared with control groups among a variety of adult malignancies. Although some reports did not demonstrate any statistically significant changes in select parameters, ${ }^{38}$ there were demonstrable positive trends. ${ }^{37}$

Our studies are the first to assess the effect of martial arts intervention in a pediatric population where the participants predominantly suffered from cancer-related pain. In evaluating pre- to post-test scores, it is important to acknowledge the possibility of "regression to the mean" where the study group will eventually trend to the population mean. However, the regression can occur in either direction. In our case, we have demonstrated that the intervention consistently reduced the perception of pain in an ethnically diverse pediatric population and that the major pain reduction was observed when the baseline preintervention scores 1) were $>3,2$ ) were most robust when pain scores were $>5,3$ ) positively reduced preintervention pain scores in $>85 \%$ of the participants, and 4) had better pain score reductions with increased age. Furthermore, we have shown an overall reduction in reported pain scores of $\geq 40 \%$ as a result of this program.

It is interesting to note that this program is beneficial in the pediatric population among various age groups. Pain in the pediatric population is unique as it encompasses various stages of development and thus may translate pain registration and reporting differently as children mature. As many as $40 \%$ of children and adolescents complain of pain that occurs at least once weekly, and chronic pain affects at least $15 \%-20 \%$ of children. Furthermore, just as chronic pain is more prevalent in women than men, girls report more pain than boys. ${ }^{39}$ Each year, 1.5 million children, irrespective of malignancy, undergo surgical procedures, and many receive inadequate pain relief; in $20 \%$ of cases, the pain can become chronic thus creating a lifelong medical issue. ${ }^{40,41}$ On a larger scale, failure to intervene early in children's pain may lead to impairment in functioning and disruption in families. Unaddressed pain heightens anxiety and fear, which, in turn, can increase perception of pain. ${ }^{42}$

Perception of pain in pediatric medicine is complex and entails physiological, psychological, behavioral, and developmental factors. Although health care professionals often prefer practical methods, which reliably track the child's pain experience and pain control over time, researchers tend to focus on tools which are proven for reliability with different observers. ${ }^{43}$ To this end, three main methods are currently used to measure pain intensity: selfreport, behavioral, and physiological measures. Self-report measures are optimal and the most valid. Both verbal and nonverbal reports require a certain level of cognitive and language development for the child to understand and give reliable responses. Children's capability to describe pain 
increases with age and experience and changes throughout their developmental stages. ${ }^{44}$ An additional variable often promulgated in the medical milieu is that children do not feel pain the way adults $\mathrm{do}^{45}$ and that pain in adolescent patients is often underestimated and under treated ${ }^{46}$ since adolescents tend to minimize or deny pain, especially in front of parents and friends, and some adolescents regress in behavior under stress. ${ }^{45}$ In light of this, it is thus quite remarkable that this program is able to engender significant pain reduction in a wide range of age groups (3-19 years) and that older patients, in contrast to conventional thinking, actually demonstrated a more robust reduction to pain, thus providing applicability to a large proportion of the childhood population in pain.

Although there have been reports of other alternative modalities used in childhood cancers including faith healing, massage, vitamins, chiropractic, and relaxation, ${ }^{47}$ many of these interventions were instituted to cope with disease symptoms and side effects of medications and were often incorporated when families were dissatisfied with conventional medical care. ${ }^{48}$

A unique strength of this program and the therapeutic intervention it provides the concept of "teaching the world" a psychosocial projection of one's own power to enable another in pain to surmount such, thus facilitating a groupthink mentality, which has been reported as a successful value-added component in other disease states ${ }^{49}$ where those in pain help and empower each other to decrease the registration of pain. The distillation of this intervention "Power, Peace, Purpose"TM (the organization's tag line/ brand) thus becomes a mantra for the patient to incorporate these concepts at any time, during and after the intervention, where pain in any definition needs to be addressed. Furthermore, the program has been incorporated into the medical landscape of numerous children's hospitals in the US, as well as other countries, and is thus well received in the allopathic domain as it pertains to pediatric cancer management.

There are, however, limitations to our observations that would benefit from additional study. The degree to which intervention should be instituted and the frequency, which would be considered ideal, require further study. These studies were derived from sequential categorization of pain scores from participants in the program collected as they participated, without any a priori power analysis or detailed criteria for patients' involvement. A successful intervention would likely also be bolstered by the reinforcement of participating family members, treating clinicians, friends, and other children with cancer. Whether these collective components or individual isolated variables would contribute to a participant being a more likely "responder" to the intervention, as we have observed in $\sim 85 \%$ of our participants, or whether the physical (hard) or meditative (soft) martial arts intervention approaches are more suitable for one participant over another is unknown. These comprise opportunities identified from our current studies in that such variables were not accounted for and may be valuable to incorporate into a streamlined intervention for more optimal pain reduction. In addition, the duration of intervention may be improved by initially increasing the frequency (per week or month) with subsequent maintenance as the patient becomes well versed with the modalities and can integrate them into care in a nonclass setting. Furthermore, the short-term duration of interventions in most of the participants in the current studies (less than four sessions in most) and the lack of consecutive visits may reduce the long-term effects of Qigong/Tai Chi/martial arts on cancer pain; thus, the optimal duration of such intervention has yet to be defined.

In alignment with other alternatives, including Nia and Hypnosis, which are incorporated into diseases including malignancy, ${ }^{50,51}$ it would be ideal to maximize such martial arts-based therapeutic interventions since they are less costly, yet empowering, which synergize and can likely augment conventional allopathic therapy toward the benefit of the patient.

\section{Conclusion}

Martial arts-based therapeutic interventions can be quite effective in mitigating pain in childhood cancer. Such interventions can be empowering and well received by the patient and his or her family, thus further facilitating its beneficial effects. Additional studies to determine duration and frequency of participation in addition to cost reduction and objective reporting (laboratory, inflammatory, and metabolic markers) can help streamline effective integration of the martial arts into pediatric oncology and other medical practices.

\section{Acknowledgments}

The abstract of this paper was presented at the American Society of Hematology 55th Annual Meeting December 7-10, 2013, New Orleans, LA, as a poster presentation with interim findings. The poster's abstract was published in Blood, November 2013; 122: 5588.

\section{Disclosure}

The authors report no conflicts of interest in this work. 


\section{References}

1. Siegel DA, King J, Tai E, Buchanan N, Ajani UA, Li J. Cancer incidence rates and trends among children and adolescents in the United States, 2001-2009. Pediatrics. 2014;134(4):e945-e955.

2. Silver JK, Baima J, Newman R, Galantino ML, Shockney LD. Cancer rehabilitation may improve function in survivors and decrease the economic burden of cancer to individuals and society. Work. 2013;46(4):455-472.

3. Kuo KL, Saokaew S, Stenehjem DD. The pharmacoeconomics of breakthrough cancer pain. J Pain Palliat Care Pharmacother. 2013;27(2): $167-175$.

4. Martin MY, Pisu M, Kvale EA, Johns SA. Developing effective cancer pain education programs. Curr Pain Headache Rep. 2012;16(4): $332-342$.

5. Sieberg CB, Manganella J. Family beliefs and interventions in pediatric pain management. Child Adolesc Psychiatr Clin N Am. 2015;24(3): 631-645.

6. Palermo TM, Valrie CR, Karlson CW. Family and parent influences on pediatric chronic pain: a developmental perspective. Am Psychol. 2014; 69(2):142-152.

7. Mazur A, Radziewicz Winnicki I, Szczepański T. Pain management in children. Ann Agric Environ Med. 2013;1(Spec no. 1):28-34.

8. Birmingham PK. Recent advances in acute pain management. Curr Probl Pediatr. 1995;25(3):99-112.

9. Czarnecki ML, Simon K, Thompson JJ, et al. Barriers to pediatric pain management: a nursing perspective. Pain Manag Nurs. 2011;12(3): 154-162.

10. Habich M, Wilson D, Thielk D, et al. Evaluating the effectiveness of pediatric pain management guidelines. J Pediatr Nurs. 2012;27(4): 336-345.

11. Lee M, Khan MM. Gender differences in cost-related medication non-adherence among cancer survivors. J Cancer Surviv. 2016;10(2): 384-393.

12. Ghatak N, Trehan A, Bansal D. Financial burden of therapy in families with a child with acute lymphoblastic leukemia: report from north India. Support Care Cancer. 2016;24(1):103-108.

13. Bender BG. Can health care organizations improve health behavior and treatment adherence? Popul Health Manag. 2014;17(2):71-78.

14. Weiman MG. Case management. A means to improve quality and control the costs of cure in children with acute myelogenous leukemia. J Pediatr Hematol Oncol. 1995;17(3):248-253.

15. Manor B, Lough M, Gagnon MM, Cupples A, Wayne PM, Lipsitz LA. Functional benefits of tai chi training in senior housing facilities. $J \mathrm{Am}$ Geriatr Soc. 2014;62(8):1484-1489.

16. Yu R, Woo J, Chan AS, Sze SL. A Chinese Chan-based mind-body intervention improves psychological well-being and physical health of community-dwelling elderly: a pilot study. Clin Interv Aging. 2014;9:727-736.

17. Baxter A, J P Francis A. Positive impact of Tai Chi Chuan participation on biopsychosocial quality of life compared to exercise and sedentary controls: a cross-sectional survey. J Complement Integr Med. 2013;10(1): $165-174$.

18. Wang C. Role of Tai Chi in the treatment of rheumatologic diseases. Curr Rheumatol Rep. 2012;14(6):598-603.

19. Lee KY, Jeong OY. The effect of Tai Chi movement in patients with rheumatoid arthritis. Taehan Kanho Hakhoe Chi. 2006;36(2):278-285.

20. Wang C, Schmid C, Rones R, et al. Tai Chi is effective in treating fibromyalgia: a randomized controlled trial. NEngl J Med. 2010;363(8): $743-754$.

21. Wang C, Collet JP, Lau J. The effect of Tai Chi on health outcomes in patients with chronic conditions: a systematic review. Arch Intern Med. 2004;164(5):493-501.

22. Wang C, Raveendhara B, Ramel J, et al. Tai Chi on psychological wellbeing: systemic review and meta-analysis. BMC Complement Altern Med. 2010;23:1186-1472.
23. Uhlig T, Larsson C, Hjorth A-G, Ødegard S, Kvien TK. No improvement in a pilot study of tai chi exercise in rheumatoid arthritis. Ann Rheum Dis. 2005;64(3):507-509.

24. Li F, Harmer P, Fitzgerald K, et al. Tai chi and postural stability in patients with Parkinson's disease. NEngl J Med. 2012;366(6):511-519.

25. Ng SM, Wang CW, Ho RT, et al. Tai chi exercise for patients with heart disease: a systematic review of controlled clinical trials. Altern Ther Health Med. 2012;18(3):16-22.

26. Zeng Y, Luo T, Xie H, Huang M, Cheng AS. Health benefits of qigong or tai chi for cancer patients: a systematic review and meta-analyses. Complement Ther Med. 2014;22(1):173-186.

27. Ho TJ, Ho LI, Hsueh KW, et al. Tai Chi intervention increases progenitor CD34(+) cells in young adults. Cell Transplant. 2014;23(4-5):613-620.

28. Chyu MC, Zhang Y, Brismée JM, et al. Effects of martial arts exercise on body composition, serum biomarkers and quality of life in overweight/ obese premenopausal women: a pilot study. Clin Med Insights Womens Health. 2013;6:55-65.

29. Velloso CP. Regulation of muscle mass by growth hormone and IGF-I. Br J Pharmacol. 2008;154(3):557-568.

30. Llorens-Martin M, Torres-Aleman I, Trejo JL. Mechanisms mediating brain plasticity: IGF1 and adult hippocampal neurogenesis. Neuroscientist. 2009;15(2):134-148.

31. Chen Z, Meng Z, Milbury K, et al. Qigong improves quality of life in women undergoing radiotherapy for breast cancer: results of a randomized controlled trial. Cancer. 2013;119(9):1690-1698.

32. Janelsins MC, Davis PG, Wideman L, et al. Effects of Tai Chi Chuan on insulin and cytokine levels in a randomized controlled pilot study on breast cancer survivors. Clin Breast Cancer. 2011;11(3):161-170.

33. Mustian KM, Katula JA, Gill DL, Roscoe JA, Lang D, Murphy K. Tai Chi Chuan, health-related quality of life and self-esteem: a randomized trial with breast cancer survivors. Support Care Cancer. 2004;12(12): 871-876.

34. Lam SWY. A Randomized, Controlled Trial of Guolin Qigong in Patients Receiving Transcatheter Arterial Chemoembolization for Unresectable Hepatocellular Carcinoma [master dissertation]. Hong Kong: The University of Hong Kong; 2004.

35. Mustian KM, Katula JA, Zhao H. A pilot study to assess the influence of Tai Chi Chuan on functional capacity among breast cancer survivors. J Support Oncol. 2006;4(3):139-145.

36. Oh B, Butow PN, Mullan BA, et al. Effect of medical qigong on cognitive function, quality of life, and a biomarker of inflammation in cancer patients: a randomized controlled trial. Support Care Cancer. 2012; 20(6):1235-1242.

37. Sprod LK, Janelsins MC, Palesh OG, et al. Health-related quality of life and biomarkers in breast cancer survivors participating in Tai Chi Chuan. J Cancer Surviv. 2012;6(2):146-154.

38. Galantino ML, Capito L, Kane RL, Ottey N, Switzer S, Packer L. The effects of Tai Chi and walking on fatigue and body mass index in women living with breast cancer: a pilot study. Rehabil Oncol. 2003;21: 17-22.

39. Goodman JE, McGrath PJ. The epidemiology of pain in children and adolescents: a review. Pain. 1991;46(3):247-264.

40. Zeltzer LK, Schlank CB. Conquering Your Child's Chronic Pain: A Pediatrician's Guide for Reclaiming a Normal Childhood. New York, NY: HarperCollins; 2005.

41. Zeltzer LK, Anderson CT, Schechter NL. Pediatric pain: current status and new directions. Curr Probl Pediatr. 1990;20(8):415-486.

42. Anand KJ, Scalzo FM. Can adverse neonatal experiences alter brain development and subsequent behavior? Biol Neonate. 2000;77(2):69-82.

43. Morton NS. Pain assessment in children. Paediatr Anaesth. 1997;7(4): 267-272.

44. Abu-Saad HH, Hamers JPH. Decision-making and paediatric pain: a review. J Adv Nurs. 1997;26(5):946-952.

45. Hagan JF Jr, Coleman WL, Foy JM, et al. The assessment and management of acute pain in infants, children, and adolescents. Pediatrics. 2001;108(3):793-797. 
46. McGrath PJ, Frager G. Psychological barriers to optimal pain management in infants and children. Clin J Pain. 1996;12(2):135-141.

47. Valji R, Adams D, Dagenais S, et al. Complementary and alternative medicine: a survey of its use in pediatric oncology. Evid Based Complement Alternat Med. 2013;2013:527163.

48. Neuhouser ML, Patterson RE, Schwartz SM, Hedderson MM, Bowen DJ, Standish LJ. Use of alternative medicine by children with cancer in Washington state. Prev Med. 2001;33(5):347-354.
49. Chronister J, Chou CC, Kwan KLK, Lawton M, Silver K. The meaning of social support for persons with serious mental illness. Rehabil Psychol. 2015;60(3):232-245.

50. Reis D, Walsh ME, Jones T, Young-McCaughan S. A review of Nia as an exercise option for cancer survivors. Clin J Oncol Nurs. 2014;18(6): 689-692.

51. Kravits K. Hypnosis: adjunct therapy for cancer pain management. J Adv Pract Oncol. 2013;4(2):83-88.
Pediatric Health, Medicine and Therapeutics

\section{Publish your work in this journal}

Pediatric Health, Medicine and Therapeutics is an international, peerreviewed, open access journal publishing original research, reports, editorials, reviews and commentaries. All aspects of health maintenance, preventative measures and disease treatment interventions are addressed within the journal. Practitioners from all disciplines are invited to submit

\section{Dovepress}

their work as well as healthcare researchers and patient support groups. The manuscript management system is completely online and includes a very quick and fair peer-review system. Visit http://www.dovepress.com/ testimonials.php to read real quotes from published authors.

Submit your manuscript here: http://www.dovepress.com/pediatric-health-medicine-and-therapeutics-journal 